\title{
Day late and dollar short! Delayed recurrence of recto-sigmoid cancer involving sacrum and long term surveillance
}

\author{
Ahmad S.S., Khalilullah K., Dillon K.M. \\ Department of Surgery, Letterkenny University Hospital, County Donegal, Ireland
}

Received: April 17, 2019

DOI: $10.5430 /$ css.v5n2p16
Accepted: October 8, 2019

Online Published: November 20, 2019

\begin{abstract}
Patients with colorectal cancer will develop recurrence of the disease with greater than $90 \%$ having it in the first 5 years following surgery. If detected early, may be amenable to potentially curative surgical resection. This provides the rationale for a follow-up strategy in patients with resected colorectal cancer. We report a case of a 68-year-old female who had a loco regional recurrence after 13 years of primary surgery involving the middle part of sacrum, raising the question regarding the long term surveillance.
\end{abstract}

Key Words: Loco regional rectal cancer, Total mesorectal excision, American association of clinical oncologist, National comprehensive cancer network

\section{INTRODUCTION}

Intensive follow up, after colorectal surgery, has been suggested by different guide lines as most of the recurrence occurs early in the first five years post surgery. Following rectal cancer surgical resection loco regional recurrence is the most common type of failure and can be debilitating causing significant morbidity and decreased life expectancy.

\section{REPORT OF A CASE}

A 68-year-old female presented with anal pain and difficulty in evacuation for the previous one year. She was operated for recto-sigmoid tumour and had anterior resection PT2N0M0, thirteen years ago. On examination abdomen was soft, perrectal examination did not show any fissure or mass in the rectum. Her CEA was elevated at 19.6. She had surveillance colonoscopy a year ago which was repeated again. It did not show any intraluminal recurrence. She had CT TAP done (see Figure 1) which showed $3 \mathrm{~cm}$ enhancing soft tissue mass in the anterior mid sacral area which was biopsied showing appearance consistent with the late recurrence of the previously diagnosed colorectal adenocarcinoma (see Figure 2). The tumour cells exhibit positive staining with CK 19, CK20, CDX2 and CEA while negative for CK7. She had PET CT (see Figure 3) whole body done which showed high FDG uptake in the $3 \mathrm{~cm}$ soft tissue mass in the presacral area corresponding with the tumour identified on the recent $\mathrm{CT}$. The patient was discussed in the MDM meeting and was planned for chemo radiation and possible surgery for which she was planned to be referred to a tertiary care centre.

\footnotetext{
*Correspondence: Ahmad S.S.; Email: ahmad_sohai15@yahoo.com; Address: Department of Surgery, Letterkenny University Hospital, County Donegal, Ireland.
} 

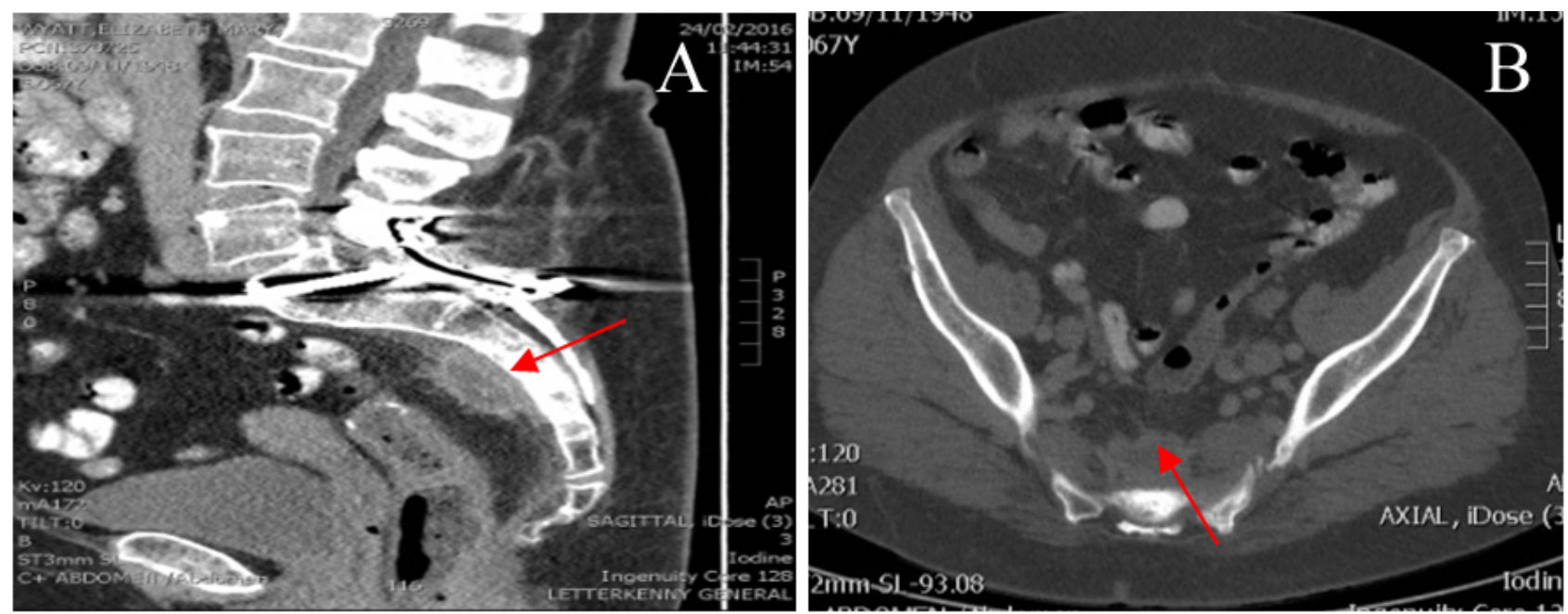

Figure 1. CT abdomen pelvis sagittal and axial planes planes showing $3 \mathrm{~cm}$ enhancing soft tissue mass in the presacral area consistent with recurrent tumour

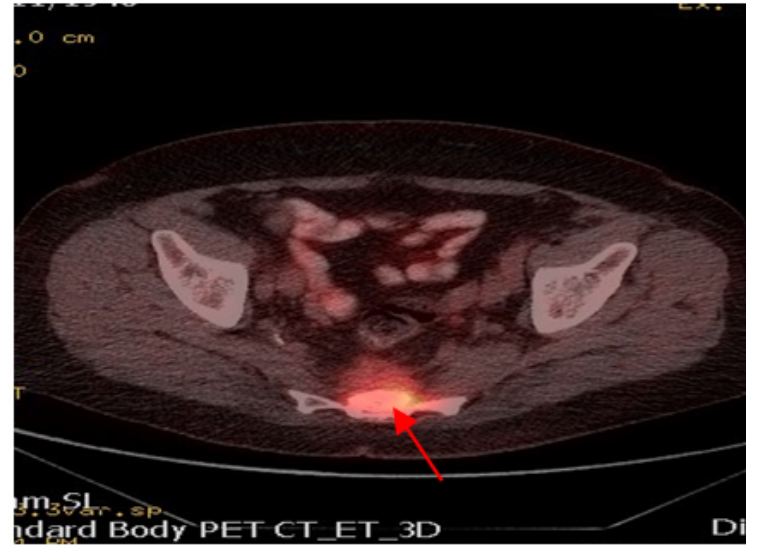

Figure 2. PET Scan showing high FDG uptake in the soft tissue mass in the presacral area corresponding with the tumour identified on the recent $\mathrm{CT}$

\section{DiscuSSION}

Recurrence of colorectal cancer (CRC) occurs in about $30 \%-40 \%$ of patients who have undergone primary curative surgical resection with majority occurring in the first two years after surgery. ${ }^{[1]}$ Various guidelines such as ASCO, NCCN, CCO advises intensive surveillance during the first 5 years after surgery with curative intent for early detection of metastatic disease or local recurrence so that surgical resection is an option for cure and improve survival. Renehan et al. ${ }^{[2]}$ and Figueredo et al. ${ }^{[3]}$ reported it detects recurrence and improves survival and reported $20 \%-33 \%$ reduction in risk of death. Tsikitis et al. in (COST trial) found that salvage rates for early and late-stage colon cancer with recurrence were the same $(35.9 \%$ vs. $37 \%) .{ }^{[4]}$

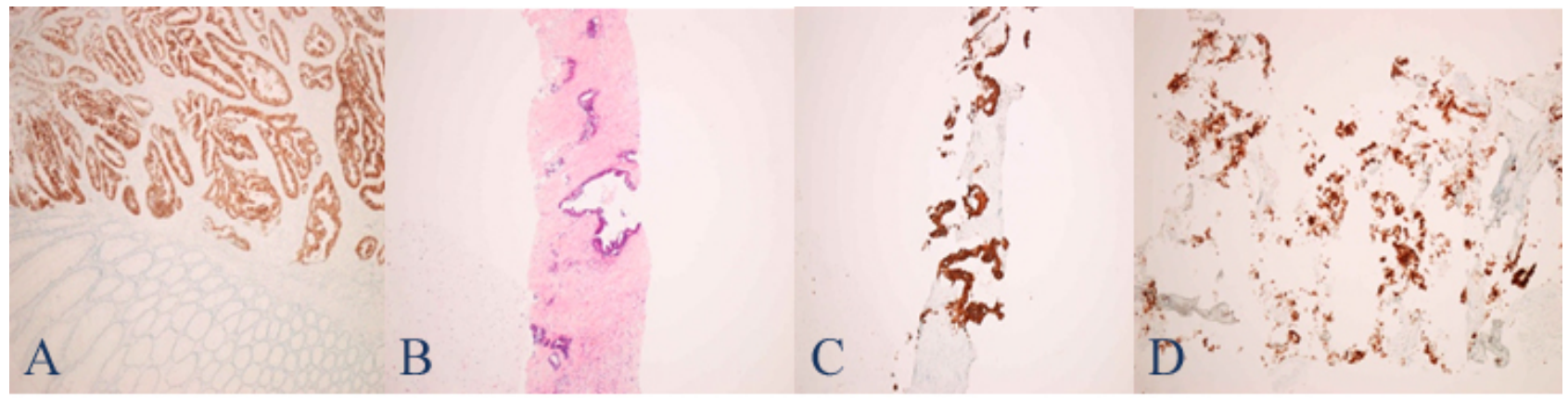

Figure 3. Histology

A. Wall of colon with infiltrating atypical glands showing positivity for CK2O; B. H\&E stain from presacral mass showing core of fibro-collagenous tissue with infiltrating atypical glands; C. IHC stain of presacral mass showing positivity for CK 20 in the atypical glands; D. High power view of the same core showing diffuse nuclear positivity of CDX2 in atypical glands 
Locally recurrent rectal cancer causes significant morbidity and mortality though total mesorectal excision and improved chemo-radio therapeutic regimens has resulted in decreased locoregional rectal cancer recurrence rates from $25 \%-40 \%$ to $4 \%-8 \% .{ }^{[5]}$ J. Faivre et al. reported 5-year cumulative rate of $12.8 \%$ for local recurrence and $25.6 \%$ for distant metastases. ${ }^{[6]}$ Ann-Marie Bouvier et al, stated overall cumulative recurrence rate of $2.9 \%$ for local recurrence and $4.3 \%$ for distant metastasis between $5-10$ years. ${ }^{[7]}$ J.C. Kim et al. reported $4.3 \%$ recurrence rate $>5$ years after surgery. ${ }^{[8]}$ All these studies prove that there is a group of patients which can have delayed loco-regional recurrence depending on the stage of the disease and need to be followed.

Delayed recurrence after 13 years is unusual, as in my patient, and raises the question about the post-operative surveillance protocols and long term surveillance. No guidelines or recommendation is available at present concerning the detection of late recurrences and leaves it to the discretion of the physician. Merkel et al, recommended at least 7-8 years of follow-up after long-term neoadjuvant radiotherapy or chemo radiotherapy for rectal cancer. ${ }^{[9]}$

Recent studies have reported higher rates of skeletal metastasis Sundermeyer et al, reported $10.4 \%$ of patients developed bony metastases. ${ }^{[10]}$ Katoh et al, reported bony metastasis of $23.7 \%{ }^{[11]}$ Time interval and survival following diagnosis is variable. Talbot et al. ${ }^{[12]}$ described a median time of 21 months and Chalkidou et al. reported a solitary tibial metastasis from rectal cancer 12 months after surgery. ${ }^{[13]}$ In our case the metastasis was diagnosed 13 years after resection of the tumour.

In sacral recurrence, the outlook is serious with severe pain and a life expectancy of only 6-7 months. ${ }^{[14]}$ The common presentation is pain, neurological deficit including motor or sphincter dysfunction. ${ }^{[15]}$ Refractory pelvic pain, tenesmus and malodorous discharge are also common. ${ }^{[16]}$ Risk factors associated with loco regional recurrence are degree of lympho-vascular invasion, differentiation and tumour size ${ }^{[17]}$ positive circumferential or distal resection margin at initial resection. Patients operated in high volume centres have lower recurrence rates. ${ }^{[18]}$ Abdominoperineal resection has been associated with higher recurrence rates than sphincter-preserving surgery. ${ }^{[19]}$ Trans-anal endoscopic microsurgery may also increase risk of recurrence rate which varies according to stage.

Most metastatic disease to the sacrum is treated with radiation, chemotherapy or both. Failure of treatment calls for surgical intervention which should be performed in a tertiary care centre. Sacrectomies are divided into high and low or total when it involves the entire sacrum, high sacrectomy involves S3 cut whereas low involves S4 and lower. Surgery is usually not indicated for $\mathrm{S} 1 / \mathrm{S} 2$ lesions because of the high risk of neurological complications. The major issue in doing these procedures are haemorrhage and neurological deficit. Sciatic nerve dysfunction is seen more in case of high sacrectomy along with urogenital dysfunction, where as patients having undergone low sacrectomy have a better quality of life from the sexual, mobility and pain management point of view. However, in a recent study by Milne et al. ${ }^{[20]}$ compared both the high and low sacral resection and reported no major difference in complications. Postoperative morbidity in this procedure is high, ranging from $15 \%-70 \%$ which increases with the complexity of resection performed. ${ }^{[21,22]}$ Moriya et al. in their study reported sacral wound dehiscence in 51\%, followed by pelvic sepsis in 39\%, walking impairment and spinal fluid leak did not occur since the preservation of the S2 sacral nerves bilaterally. ${ }^{[23]}$

\section{Conclusion}

Any symptoms post bowel cancer surgery should be looked into with high degree of suspicion and investigated. Sacral recurrence requires multidisciplinary approach in a tertiary care centre. Delayed recurrence raises the question of long term follow up and the use of another modality such as endoanal ultrasound or MRI Pelvis as a tool for follow up which needs to be looked into.

\section{CONFLICTS OF INTEREST DisClosure}

The authors declare they have no conflicts of interest.

\section{REFERENCES}

[1] Galandiuk S, Wieand HS, Moertel CG, et al. Patterns of recurrence after curative resection of carcinoma of the colon and rectum. Surg Gynecol Obstet. 1992; 174: 27-32.

[2] Renehan AG, Egger M, Saunders MP, et al. Impact on survival of intensive follow up after curative resection for colorectal cancer: systematic review and meta-analysis of randomised trials. BMJ. 2002; 324: 1-8. PMid: 1193477. https://doi.org/10.1136/bmj.32

\subsection{1 .813}

[3] Figueredo A, Rumble RB, Maroun J, et al. The members of the Gastrointestinal Cancer Disease Site Group of Cancer Care Ontario's Program in Evidence-based Care Follow-up of patients with curatively resected colorectal cancer: a practice guideline. BMC Cancer. 2003; 3: 26. PMid: 14529575. https ://doi .org/10.1186/1471 $-2407-3-26$

[4] Tsikitis VL, Malireddy K, Green EA, et al. Postoperative Surveil- 
lance Recommendations for Early Stage Colon Cancer Based on Results from the Clinical Outcomes of Surgical Therapy Trial. J Clin Oncol. 2009 Aug 1; 27(22): 3671-3676. PMid: 19564531. https://doi.org/10.1200/JC0.2008.20.7050

[5] KapiteijnE, Marijnen CAM, Nagtegaal ID, et al. Preoperative radiotherapy combined with total mesorectal excision for resectable rectal cancer. New England Journal of Medicine. 2001; 345(9): 638-646. PMid: 11547717. https://doi.org/10.1056/NEJMoa010580

[6] Manfredi S, Bouvier AM, Lepage C, et al. Incidence and patterns of recurrence after resection for cure of colonic cancer in a well-defined population. Br J Surg. 2006 Sep; 93(9): 1115-22. PMid: 16804870. https://doi.org/10.1002/bjs.5349

[7] Bouvier AM, Launoy G, Bouvier V, et al. Incidence and patterns of late recurrences in colon cancer patients. International Journal of Cancer. 2015 Nov 1; 137(9): 2133-8. PMid: 25912489. https://doi.org/10.1002/ijc. 29578

[8] Seo SI, Lim SB, Yoon YS, et al. Comparison of recurrence patterns between $\leq 5$ years and $>5$ years after curative operations in colorectal cancer patients. Journal of Surgical Oncology. 2013; 108: 9-137. PMid: 23754582. https://doi.org/10.1002/jso. 23349

[9] Merkel S, Mansmann U, Hohenberger W, et al. Time to locoregional recurrence after curative resection of rectal carcinoma is prolonged after neoadjuvant treatment: a systematic review and meta-analysis. Colorectal Dis. 2011; 13: 123-31. PMid: 19895596. https://doi.org/10.1111/j.1463-1318.2009.02110.x

[10] Sundermeyer ML, Meropol NJ, Rogatko A, et al. Changing patterns of bone and brain metastases in patients with colorectal cancer. Clin Colorectal Cancer. 2005; 5: 108-13. PMid: 16098251. https://doi.org/10.3816/CCC.2005.n.022

[11] Katoh M, Unakami M, Hara M, et al. Bone metastasis from colorectal cancer in autopsy cases. J Gastroenterol. 1995; 30: 615-8. PMid: 8574333. https://doi.org/10.1007/BF02367787

[12] Talbot RW, Irvine B, Jass JR, et al. Bone metastases in carcinoma of the rectum: A clinical and pathological review. Eur J Surg Oncol. 1989; 15: 449-52.

[13] Chalkidou AS, Boutis AL, Padelis P. Management of a Solitary Bone Metastasis to the Tibia from Colorectal Cancer. Case Rep Gastroenterol. 2009; 3: 354-359. PMid: 21103253. https ://doi .org/10 $.1159 / 000239626$
[14] Gunderson LL, Sosin H. Areas of failure found at reoperation (second or symptomatic look) following 'curative surgery' for adenocarcinoma of the rectum Cancer. 1974 Oct; 34(4): 1278 92. https://doi.org/10.1002/1097-0142(197410) $34: 4<12$ 78: : AID-CNCR2820340440>3.0.CO; $2-\mathrm{F}$

[15] Hall JH, Fleming JF. The "lumbar disc syndrome" produced by sacral metastases. Can J Surg. 1970; 13: 149-156.

[16] Bakx R, Visser O, Josso J, et al. Management of recurrent rectal cancer: a population based study in greater Amsterdam. World Journal of Gastroenterology. 2008 Oct 21; 14(39): 6018-23. PMid: 18932280. https://doi.org/10.3748/wjg.14.6018

[17] Ogiwara H, Nakamura T, Baba S. Variables related to risk of recurrence in rectal cancer without lymph node metastasis. Annals of Surgical Oncology. 1994 Mar; 1(2): 99-104. PMid: 7834447. https://doi.org/10.1007/BF02303551

[18] Martling A, Cedermark B, Johansson H, et al. The surgeon as a prognostic factor after the introduction of total mesorectal excision in the treatment of rectal cancer. British Journal of Surgery. 2002 Aug; 89(8): 1008-13. PMid: 12153626. https://doi.org/10.1046/j. 1365-2168.2002.02151. $\mathrm{x}$

[19] Tilney HS, Tekkis PP, Sains PS, et al. Factors affecting circumferential resection margin involvement after rectal cancer excision. Diseases of the Colon and Rectum. 2007 Jan; 50(1): 29-36. PMid: 17115338. https://doi.org/10.1007/s10350-006-0744-6

[20] Milne T, Solomon MJ, Lee P, et al. Assessing the impact of a sacral resection on morbidity and survival after extended radical surgery for locally recurrent rectal cancer. Ann Surg. 2013; 258: 1007-1013. PMid: 23364701. https://doi.org/10.1097/SLA.0b013e31 8283a5b6

[21] Vermaas M, Ferenschild FTJ, Verhoef C, et al. Total pelvic exenteration for primary locally advanced and locally recurrent rectal cancer. European Journal of Surgical Oncology. 2007; 33(4): 452-458. PMid: 17071043. https://doi.org/10.1016/j.ejso.2006.09.021

[22] Palmer G, Martling A, Cedermark B, et al. A population-based study on the management and outcome in patients with locally recurrent rectal cancer. Annals of Surgical Oncology. 2007; 14(2): 447-454. PMid: 17139457. https://doi .org/10.1245/s10434-006-9256-9

[23] Moriya Y, Akasu T, Fujita S, et al. Total pelvic exenteration with distal sacrectomy for fixed recurrent rectal cancer in the pelvis. Dis Colon Rectum. 2004; 47: 2047-54. PMid: 15657653. https: //doi.org/10.1007/s10350-004-0714-9 